\title{
DETERMINANDO CRENÇAS NO CUIDADO DE ENFERMAGEM A CRIANÇAS COM DOR: O CONTEXTO FAMILIAR
}

\author{
DETERMINING BELIEFS IN NURSING CARE FOR CHILDREN IN PAIN: THE FAMILY CONTEXT \\ DETERMINANDO CREENCIAS EN EL CUIDADO DE ENFERMERIA A NIÑOS COM DOLOR: \\ EL CONTEXTO FAMILIAR
}

Lisabelle Mariano Rossato-Abéde* Margareth Angelo**

\begin{abstract}
RESUMO: Este estudo buscou compreender as crenças de dor em criança e sua família para a enfermeira e suas estratégias utilizadas ao lidar com a dor da criança e sua família. Foi utilizado como referencial metodológico a Teoria Fundamentada nos Dados e como referencial teórico o Interacionismo Simbólico. Os resultados permitiram identificar um conjunto de três categorias que revelam as crenças da enfermeira determinantes do cuidado de uma criança com dor: Acreditando que a criança tem dor de diferentes naturezas, Acreditando que as pessoas envolvidas com a dor da criança sofrem e Acreditando que o papel da enfermeira na dor da criança é ajudar.
\end{abstract}

PALAVRAS CHAVE: Saúde de família; Cuidados de enfermagem; Dor; Criança.

\section{INTRODUÇÃO}

A escassez de intervenções para o alívio da dor em criança pode não se dever, como se pensa, somente à ausência de conhecimentos da enfermeira, mas, também, devido ao significado que cada enfermeira atribui à dor da criança e sua família em cada situação em particular. Este estudo, portanto, buscou compreender o significado da dor da criança e de sua família para a enfermeira e revelou a importância das crenças na vida e, consequentemente, no seu trabalho.

Ao identificar as crenças como sendo as lentes através das quais vemos o mundo, Wright et al (1996) revelam que cada pessoa tem sua própria crença baseada na sua história genética e na história de interações com os outros no mundo.

Dessa maneira, o aparecimento das crenças que norteiam o cuidar da enfermeira nos resultados deste estudo veio a constituir um caminho para possibilitar o encontro das respostas para explicar o significado que ela atribui à dor da criança e sua família. Nesse sentido, decidimos compreender melhor como a enfermeira constrói a experiência de cuidar da criança com dor e sua família, estabelecendo como objetivos deste trabalho:

- compreender as crenças da enfermeira em relação à dor da criança e sua família;

- compreender as estratégias utilizadas pela enfermeira ao lidar com a dor da criança e sua família.

\section{METODOLOGIA}

\section{REFERENCIAL TEÓRICO E METODOLÓGICO}

Optamos pela metodologia qualitativa para compreender a experiência da enfermeira ao cuidar da criança com dor bem como as estratégias utilizadas por ela em relação à dor da criança. Segundo Field \&

\footnotetext{
* Professor Assistente do Departamento de Enfermagem Materno-Infantil e Psiquiática da Escola de Enfermagem da USP, e-mail: rossato@ usp.br e angelm@usp.br

** Professor Titular do Departamento de Enfermagem Materno-Infantil e Psiquiática da Escola de Enfermagem da USP.
} 
Morse (1985), o método qualitativo é recomendado quando se conhece pouco a respeito de um fenômeno ou pretende-se descrevê-lo de acordo com o ponto de vista do sujeito, aplicando-se, portanto, à questão que norteia este estudo.

Angelo (1997) acrescenta que a Teoria Fundamentada nos Dados é uma das metodologias mais representativas desse grupo qualitativo de investigação, a qual consiste numa forma de estudar fenômenos desenvolvidos conceitualmente através de um processo de coleta e análise de dados sistematicamente conduzido. 0 resultado de todo o processo é uma teoria emergente das relações estabelecidas entre conceitos descobertos que tem como referencial teórico o Interacionismo Simbólico.

S egundo Charon (1989), o Interacionismo Simbólico atribui uma importância fundamental ao sentido que as coisas têm para o comportamento humano. 0 significado das coisas é visto como um produto social com origem na interação simbólica, na qual o ser humano define e interpreta as ações através das atividades desenvolvidas pelas pessoas enquanto elas interagem.

\section{PERCURSO METODOLÓGICO}

Participantes do estudo. Os critérios para a seleção das participantes foram as enfermeiras terem vivenciado uma experiência de cuidar de uma criança com dor e que tivesse sido significativa para elas. Foram participantes do estudo, 5 enfermeiras, que atuam em pediatria por tempo de 1 a 16 anos. As enfermeiras que participaram deste estudo foram contatadas diretamente pela pesquisadora, não havendo, portanto, um local específico para a realização das entrevistas. Explicado o propósito desta investigação, e havendo concordância em participar do estudo era agendado local e data convenientes para a realização das entrevistas.

Antes de cada entrevista foi solicitada autorização para que a mesma fosse gravada, garantindo-se sigilo quanto a sua identificação em todo o processo da pesquisa.

Coletando os dados. Foram realizadas entrevistas orientadas pelo método biográfico descrito por Denzin (1989), o qual propõe uma estratégia para a coleta de estórias e narrativas que abordam um momento na vida da pessoa.

Denzin (1989) define uma narrativa como uma estória que fala de uma seqüência de eventos que são significativos para o narrador e sua audiência. Uma narrativa sendo uma estória, tem uma estrutura, um começo, um meio e um fim. Possui também uma seqüência lógica que faz sentido para o narrador. Uma narrativa relata os eventos numa seqüência temporal e causal, descrevendo assim uma seqüência de eventos que aconteceram. Para Denzin (1989), experiências biográficas significantes são contadas e re-contadas sob a forma de narrativa. Nesse sentido, a estratégia de narrativa mostrou-se adequada aos propósitos do estudo.

As entrevistas realizadas foram semi-estruturadas e norteadas pela questão:

"Conte-me uma experiência significativa que você tenha vivenciado com uma criança com dor."

Analisando os dados. Inicialmente, foi realizada, pela pesquisadora, a transcrição na íntegra das fitas com as entrevistas, a partir da leitura exaustiva das transcrições, foi realizada a codificação dos dados significativos. A análise dos dados ocorreu simultaneamente à coleta dos mesmos, conforme recomendam Strauss; Corbin (1990) realizando-se a codificação aberta e sua categorização, conforme preconizam Glaser; Strauss, (1967).

Embora a Teoria Fundamentada nos Dados tenha como objetivo a construção de um modelo teórico, esta investigação pretendeu a descrição de categorias de significados, que face ao processo de comparação constante, possibilitou a identificação de categorias explicativas do significado que a enfermeira atribui à dor da criança.

A Teoria Fundamentada nos Dados caracteriza-se por ser uma forma em que os dados são manejados pelo pesquisador, e sendo uma construção constante, permite que a análise dos dados seja interrompida em qualquer fase e os resultados relatados, conforme preconizam Chenitz; S wanson, (1987). 


\section{RESULTADOS}

Os resultados desse estudo permitiram emergir um conjunto de crenças que não somente estava presente na experiência, como também determinava o significado da mesma para a enfermeira.

Neste sentido, direcionando a análise para este tema, configuraram-se as categorias deste estudo que revelam as crenças da enfermeira determinantes do cuidado de uma criança com dor: Acreditando que a criança tem dor de diferentes naturezas, Acreditando que as pessoas envolvidas com a dor da criança sofrem e Acreditando que o papel da enfermeira na dor da criança é ajudar.

Cada uma destas categorias será apresentada utilizando-se para a descrição as subcategorias e componentes da mesma construídos no processo de análise.

\section{Acreditando que a criança tem dor de diferentes naturezas}

A enfermeira classifica a natureza da dor da criança de duas formas: A- Dor-Física e B- Dor-Sofrimento e esta classificação ocorre a partir da compreensão que ela faz da natureza da dor, além de determinar todo 0 processo de atuação da enfermeira diante da dor da criança.

\section{A- Dor Física}

Ao revelar sua crença a respeito da natureza física da dor da criança, a enfermeira contempla os aspectos fisiológicos da dor, sobretudo os manifestados por dados clínicos e comportamentais da criança.

A enfermeira considera a existência da dor no momento em que a criança verbaliza, constatando o sofrimento da criança porque refere dor. A enfermeira acredita na queixa de dor da criança.

"ela quando tinha a dor que referia, que falava, estava sentindo dor"

A enfermeira acredita na dor da criança quando consegue identificar uma causa, ou porque tem um diagnóstico. A enfermeira confia na queixa da criança porque sabe que tem um problema físico que precisa ser tratado. A enfermeira constata que a dor da criança tem uma causa clínica que a faz sentir dor.

"E aí depois foi feito todos os exames que descobriu que ela tinha realmente um problema físico que precisou ser tratado"

Além de acreditar na existência de uma doença física, a enfermeira percebe e valoriza a reação de dor da criança face a diferentes situações, acreditando que tem dor porque reage à manipulação.

"Acho que essa criança ficou com dor porque ela tinha uma paralisia espástica e pela estimulação, pela quantidade de estímulos, de manipulação que estava sendo feito"

No momento em que a criança é submedicada e continua referindo dor, torna-se verdadeiro para a enfermeira a existência física da dor. A enfermeira verifica que a criança continua referindo dor após receber uma dose insuficiente de medicamento porque a dor volta quando submedicada.

"ela acalmava naquele instante, mas logo depois a dor vinha, continuava porque não tinha sido uma dose suficiente"

A enfermeira observa a criança evitando certas atividades por temer o início da dor. A enfermeira constata que a dor está presente porque limita as atividades da criança. A enfermeira reconhece a dor causando limitação à criança para a realização de suas atividades físicas.

"pelo que eu percebi nela limitava muito as atividades dela, as atividades, assim, com os amigos, com esporte"

A enfermeira verifica que a criança tem um desconforto físico porque mantém a posição antálgica. A constatação da enfermeira de um problema físico na criança através da observação de um desvio no seu corpo ou percebendo a criança utilizando, continuamente, a posição antálgica para aliviar a dor sentida, leva a enfermeira a acreditar na dor.

"e ela estava já ficando com desvio por conta dessa posição" 
Porque tem face de dor é quando a enfermeira valoriza a fisionomia de dor da criança. A enfermeira percebe que a criança sente dor através da observação da face de dor que ela manifesta. A enfermeira reconhece, na expressão facial da criança, a dor sentida.

"então a gente sentia que ele estava com alguma coisa incomodando e uma dor bastante intensa"

Ao admitir que a criança tem dor mesmo estando medicada, faz com que a enfermeira acredite na queixa da criança porque a dor volta sempre, revelando a existência de um componente físico da dor.

"mas a dor era contínua, a dor voltava sempre por mais que medicasse, por mais que tentasse tudo"

Ao verificar que a dor da criança aumenta quando percebe que as atenções deixam de ser exclusivas para ela, e que, ao receber uma dose menor de medicação, melhora em seguida porque a dor passa com uma subdose, a enfermeira acredita que há algo emocional atuando na dor física. Além disso, observa quando a criança menciona melhora da dor até mesmo com um placebo, corroborando sua idéia de uma dor física de causa emocional.

"quando ela percebia que estavam deixando de dar um pouquinho mais de atenção para ela, a dor vinha de uma forma, assim, enorme, aí dava, assim, uma medicação, às vezes, dava uma subdose e a dor passava rapidamente"

O componente emocional da dor física é ainda observado quando a enfermeira percebe a criança tendo certos comportamentos porque quer chamar a atenção em relação à dor, principalmente, quando se utiliza da dor como pretexto para deixar de fazer algo que não gosta. A enfermeira fica atenta às observações da família de que a criança supera sua dor para realizar suas atividades preferidas, dando a entender que a dor tem um componente emocional.

"durante o dia ela até tinha as atividades desligada, então isto dava a entender que tinha algum componente, assim, chamando a atenção"

Da mesma maneira a enfermeira reconhece que a criança, quando mantém-se distraída, esquece da dor, não necessitando de medicamento. Estes comportamentos de que a criança se desliga da dor enquanto brinca, porque esquece da dor quando está distraída, fornecem indícios à enfermeira não apenas sobre a manifestação da dor, mas também sobre formas de manejá-la.

"porque a gente ficava junto, saía, passeava, ela ia brincar com a minha filha, então a dor, acho que ela esquecia, ela distraía"

B- Dor-Sofrimento

É a interpretação que a enfermeira faz da dor da criança não relacionada às evidências que determinam uma dor física.

A enfermeira acredita que a criança tem dor-sofrimento, porque 0 ambiente desencadeia dor. A enfermeira acredita que fatores próprios do ambiente, como a luminosidade, ruídos e as pessoas ali presentes, acarretam dor-sofrimento à criança, sobretudo quando esta é muito pequena.

“às vezes de ouvir a nossa voz o comportamento dela já muda, luminosidade, eu acredito que isso desencadeia dor"

A enfermeira acredita que também sua figura, intensifique para a criança a vivência da dor-sofrimento, porque tem medo da figura da enfermeira. Nesse sentido, a enfermeira percebe o profissional como um fator de dor-sofrimento para a criança.

"porque na verdade quando você chega de avental branco, ele já foi colhido sangue, já foi tudo, você põe a mão na criança ele vai sempre achar que você vai fazer alguma coisa dolorosa"

A enfermeira reconhece que a criança tem dor-sofrimento porque não sabe o que vai acontecer. Para a enfermeira, imaginar a criança percebendo as pessoas como estranhas sem ter ninguém para apoiá-la e desconhecendo o que vai acontecer com ela é motivo para desencadear a dor-sofrimento. 
"agora se não tem ninguém, eu vou ficar olhando para o furo do meu braço que está doendo e que pode sangrar, eu não sei se vai sangrar, eu não sei o que que vai sair"

A enfermeira reconhece que a criança sente dor-sofrimento porque sente-se sozinha, não tendo apoio quando vai sentir dor. A enfermeira considera que a criança sente dor-sofrimento porque não tem alguém em quem confie perto dela.

"ela (família) prefere sair e aí a criança já reafirma, olha, tá vendo na pior hora ela saiu"

$\mathrm{Na}$ experiência de cuidar da criança com dor, a enfermeira percebe não apenas o sofrimento da criança e da família, mas também o seu próprio.

Dessa maneira, a categoria Acreditando que as pessoas envolvidas no cuidado da criança com dor sofrem é composta por três subcategorias: A- Acreditando que a criança com dor sofre, B- Acreditando que a família da criança com dor sofre e C-Acreditando que a enfermeira sofre com a dor da criança .

\section{A- Acreditando que a criança com dor sofre}

É o aspecto da crença que revela a enfermeira percebendo o sofrimento da criança vivenciando dor porque tem limitações, sendo privada de realizar atividades físicas próprias da idade devido a dor. A enfermeira considera a dor um fator de sofrimento para a criança por não poder desempenhar ações próprias de seu papel de criança, como brincar.

"ela começou, assim, a diminuir a parte de atividade física na escola, ela sofria porque, às vezes, ela queria fazer aquela atividade e não podia porque estava com dor, então ela tinha limitação, ela sofria com a dor propriamente dita"

Considerando um grande fator de sofrimento para a criança o fato de sua dor ser real, existir e de sentila, a enfermeira acredita que a criança sofre porque tem um dano físico.

"eu percebia que ela sentia, assim, ela sofria com a dor, sofria o dano físico"

Ao cuidar da criança com dor a enfermeira percebe que é um sofrimento para a criança desconhecer a duração bem como a intensidade da dor que está vivendo. A enfermeira reconhece o sofrimento da criança porque não tem controle da sua dor.

"a criança com dor sofre porque eu acho, eu acho que ela não sabe o quanto a dor vai aumentar ou diminuir"

A enfermeira acredita que a criança sofre porque vê-se sozinha durante os procedimentos. A enfermeira constata que a criança sente falta de pessoas significativas, como a sua família, a sua volta quando sentese ameaçada.

"você está sem pai nem mãe, te seguram, te prendem, pedem para você não chorar porque não vai doer, te enfiam uma "baita" de uma agulha"

\section{B- Acreditando que a família da criança com dor sofre}

A enfermeira reconhece o sofrimento da família por desconhecer a causa da dor da criança e com isso percebe a família bastante insegura e amedrontada com as conseqüências da dor da criança porque tem medo do que possa ser.

"todo mundo apavorado com a possibilidade de ser uma coisa maligna"

P or outro lado, a enfermeira nota a família sofrendo por não conseguir descobrir uma solução para a dor da criança. A enfermeira percebe a família sofrendo porque não resolve o problema, mostrando-se incrédula em relação ao alívio da dor da criança.

"ela já tinha pesquisado, já tinha feito ultra-som, já tinha feito todos esses exames, até os mais sofisticados e não descobriam nada, ninguém descobria o que a menina tinha, assim, fisicamente" 
A enfermeira, ao olhar para a família, a vê sofrendo por sentir-se impotente para atuar no alívio da dor da criança porque não sabe o que fazer. A enfermeira constata que não pode fazer nada para aliviar a dor da criança e percebe que a família está sentindo-se de mãos atadas, o que gera grande sofrimento.

"a família sofre porque não sabe o que fazer para tirar aquela dor, ela se sente totalmente impotente"

A enfermeira reconhece o sofrimento da família porque vê a criança sofrer quando é submetida a procedimentos inevitáveis, porém dolorosos. A enfermeira acredita que a família sente-se impotente diante da situação, sofrendo por ver a criança sentir dor e não poder cessá-la.

"a mãe, por exemplo, ficava extremamente ansiosa por que a filha estava com uma dor"

A enfermeira percebe a família temendo medicar a criança para a dor porque tem medo de viciar a criança. A enfermeira considera o temor da família em utilizar quantidades de medicamento que possam expor a criança a uma dependência.

"ela tinha essa preocupação de que a criança fosse ficar viciada na novalgina, no tylenol, enfim, no medicamento. Ela tinha muito medo, ela tinha pavor praticamente disso"

C- Acreditando que a enfermeira sofre com a dor da criança

Quando a enfermeira entra em contato com o sofrimento vivenciado pela criança com dor e sua família, depara-se com seus próprios sentimentos.

A enfermeira percebe o próprio sofrimento quando se vê realizando procedimentos dolorosos na criança. Ela sente pena de ter que fazer um procedimento na criança e sofre, sentindo-se responsável pela dor porque vê que a criança sofre não podendo aliviá-la.

"eu acho que as crianças com a dor sofrem , primeiro porque eles são seres humanos, segundo porque eu fico imaginando, "poxa" são tão pequenininhos ali"

A enfermeira sofre, também, ao colocar-se no lugar da família, porque vê que a família sofre vivenciando o sofrimento da criança sem poder fazer nada para ajudá-la, percebendo-a descrente com a vivência da situação da criança sentindo a dor. Ela sofre, também, quando percebe a família sendo incompreendida pela equipe.

"eles estavam sofrendo, assim, porque eles já estavam descrentes, desesperados, porque eram $24 \mathrm{~h}$ por dia essa criança gritando no colo de uma mãe"

Interagindo com a situação, a enfermeira começa a perceber-se vulnerável e, ao mesmo tempo, tem que agir corretamente, racionalmente. A enfermeira sofre porque sente medo por viver este sentimento e ao mesmo tempo ser avaliada pelo seu desempenho no local de trabalho.

"eu tenho medo do que a enfermeira chefe vai falar... ser avaliada a todo momento, entendeu"

A enfermeira sofre porque fica indignada com o tratamento dado à criança ao perceber uma ausência de alívio na dor da criança, mesmo após a criança ser submetida a um procedimento doloroso. Fica incomodada vendo a criança não ser medicada, constatando que, às vezes, não é feito nada para aliviar a sua dor porque os profissionais de saúde não conseguem descobrir a causa dessa dor.

"é raro você ver prescrito algum analgésico, alguma coisa lá... Volta de cirurgia não está prescrito nada, nenhum analgésico"

Da mesma forma, a enfermeira ressente-se ao perceber a família sendo desconsiderada pela equipe de saúde em relação ao que acontece com a criança. A enfermeira sofre porque fica indignada com o tratamento dado à família quando nota a restrição de explicações fornecidas a ela sobre o que está sendo feito com a criança.

"as pessoas não conversam, não explicam, fazem medicação, assim, não dão atenção nenhuma, as mínimas coisas que acontecem ali, a família é totalmente posta de lado"

Sentir-se despreparada para lidar com a situação de dor da criança provoca, na enfermeira, sentimentos de insegurança. A enfermeira acredita que sofre porque sente-se insegura ao perceber suas limitações para atender a criança com dor, principalmente quando a enfermeira vivencia a experiência no início de sua atividade profissional. 
"eu quero ajudar a família mas eu não sei por onde, por onde começar"

A enfermeira também sofre porque percebe que a equipe sofre quando vivencia o cotidiano da criança sentindo dor. A necessidade de aliviar a dor da criança é evidenciada quando a enfermeira é procurada pela equipe para resolver a situação de dor.

"todas as pessoas que trabalham nessa UTI ouvindo essa criança gritar... esse sofrimento estava sendo não só para criança, para os familiares, mas também toda a equipe que estava trabalhando com essa criança"

S eja por causa das poucas habilidades para lidar com a situação ou por tentar dar conta de todas as demandas, a enfermeira restringe suas expectativas de cuidado, o que a leva a se sentir frustrada no cuidado à criança porque não faz tudo que acredita.

"acho que é assim, a minha crença é uma e o que eu consigo fazer não chega a atingir toda a minha crença, eu ainda não consigo fazer tudo o que eu acredito, entendeu, em termos assim, o que eu acredito em mim como enfermeira"

A enfermeira sofre porque sente-se impotente ao ter que realizar várias vezes o mesmo procedimento na criança, fazendo-a sentir dor. Acredita, também, que não consegue fazer muita coisa, ainda, para aliviar a dor da criança e até mesmo deixá-la mais confortável.

"eu tive que colher três dextros de um menininho de três anos que era apaixonada por ele, mas a dextro dava muito baixa e não estava compatível com o exame laboratorial e tinha que colher... ele sentia a dor, ele chorava"

A enfermeira sente-se despreparada a a assumir o cuidado da criança com dor porque sente-se perdida para enfrentar o desafio gerado pelo desconhecimento das suas habilidades, sobretudo quando se percebe inexperiente para intervir ou mesmo compartilhar a situação de dor vivenciada pela criança e pela família.

"eu não me sinto uma enfermeira ainda, eu me sinto totalmente crua, totalmente perdida, ainda, tanto por falta de conhecimento técnico, por falta de conhecimento científico"

\section{Acreditando que o papel da enfermeira na dor da criança é ajudar}

Esta categoria revela que a enfermeira acredita que a criança tem dor e percebe 0 sofrimento não apenas da criança, mas também da família e o seu próprio, sendo motivada a tomar algumas decisões como tentar ajudar a criança e a família fazendo alguma coisa para aliviar a dor, bem como articular a equipe para otimizar a resolução da dor da criança.

Desta maneira, a categoria Acreditando que o papel da enfermeira na dor da criança é ajudar é composta por 3 Subcategorias: A- Tentar ajudar a criança, B- Tentar ajudar a família e C- Articular a equipe.

\section{A- Tentar ajudar a criança}

A enfermeira acredita que, ao cuidar de uma criança sentindo dor, o passo inicial para ajudá-la deve ser confiar na queixa de dor dessa criança. Desta forma dando força à voz da criança, permitindo-Ihe expressar-se como puder.

"acho que o meu papel era, simplesmente, de estar acreditando, primeiro que a criança estava com dor"

Ao tentar ajudar a criança, acreditando em sua dor, a enfermeira busca conhecer melhor a dor sabendo que esse conhecimento poderá auxiliá-la a esclarecer a causa da dor e compreender melhor as manifestações da criança com dor. Para tanto, entra em contato com a criança e tenta ajudá-la identificando a origem da dor através de observações do seu comportamento, de pesquisas a respeito da dor objetivando entender a sua causa.

"a gente tentava identificar o que desencadeava a dor, tentava identificar que momentos que a dor aparecia com maior freqüência, tentava relacionar isso com alguma coisa, tipo assim, ela não pôde fazer determinada coisa e a dor apareceu ou não" 
A enfermeira percebe a necessidade de saber olhar para a criança ficando atenta ao que ela diz, conseguindo intervir de uma maneira melhor no alívio da dor. É a enfermeira aprendendo a olhar para a criança para saber o que se passa com ela.

"quando a gente não está naquela corrida que eu te falei, quando você consegue sair desse miolo que parece que passa um furacão e você entra no meio? Quando você consegue não entrar, você consegue perceber o que a criança está querendo dizer para você"

A enfermeira necessita estar fazendo alguma coisa para aliviar a dor da criança. A enfermeira age medicando corretamente a criança com dor.

"ela tem dor e tem que ser tratada essa dor adequadamente, não tem que ter medo de dar o remédio"

Ela também reconhece que medicando a criança com fármacos mais potentes, fica evidente a necessidade de atuar mais intensamente para o alívio da sua dor.

"então a gente começou, entramos com um tratamento com medicamento, com opiáceo, com outros tipos de analgésicos"

A enfermeira acrescenta outras formas de ajudar a criança quando trabalha com outras opções além de medicação analgésica.

"trabalhava com outras opções que não só a medicamentosa, colocar bolsinha de água quente no local para ver se aliviava a dor, fazer exercício postural para ver se não era aquilo que estava, porque quem sabe com exercício era a postura que não estava bem"

Ao perceber a criança com dor, a enfermeira tenta fazer alguma coisa principalmente para aliviá-la relaxando a criança, utilizando-se de estratégias, como, por exemplo, a massagem.

"eu vou tentar fazer alguma coisa para poder relaxar, porque a impressão que me dava é que ele tinha os braços, os membros muito contraídos, e isso que parecia estar dando a dor na criança"

A enfermeira entende o significado, para a criança, de estar internada colocando-se no seu lugar e sofre ao perceber a criança sendo submetida a procedimentos repetidas vezes sem conseguir receber 0 alimento no horário correto. Constata que as pessoas preocupam-se mais com o andamento do plantão do que com 0 bem estar da criança.

"eu acho que a partir do momento que você se põe no lugar, deita naquela cama, imagina "trocentas" pessoas que você não sabe o nome... então acho que a gente tem que se policiar na sua forma de ser como profissional e nunca esquecer de se colocar no lugar da criança"

A enfermeira respeita a privacidade da criança oferecendo um espaço de tempo deixando-a descansar, podendo ficar com seus pais e com suas coisas sem ser incomodada como forma de ajudá-la, compreendendo a situação de sofrimento vivenciada pela criança.

"conversamos com o neurologista da criança que entrou com um pouco mais de medicação e o que a gente teve foi que depois de algumas horas a criança estava tranqüila, dormindo, sossegada, tranqüila"

A enfermeira acredita que, fazendo-se conhecida pela criança, torna o procedimento menos sofrido e doloroso porque a criança já consegue confiar na enfermeira.

"então você tem que primeiro se mostrar próxima da criança, do tipo, olha, eu preciso fazer isso, vai doer, mas depois a tia, se você quiser um colo a tia dá"

Ao conversar com a criança, antes de um exame, a enfermeira explica-lhe como vai acontecer e, podendo, utiliza brinquedos para facilitar o preparo e a compreensão da criança. A enfermeira percebe que preparando a criança para enfrentar um procedimento difícil e doloroso, esta sofre menos.

"o que eu acredito era, se possível, um brinquedo e mostrar o que que é" 
Ao mesmo tempo, a enfermeira percebe-se, ao longo do seu trabalho, distraindo a criança quando esta refere que a dor piorou, e não é possível medicá-la tendo que lançar mão de outras estratégias com a criança para tentar fazê-la esquecer-se da dor por algum momento, até ser medicada novamente.

"e em alguns momentos a gente usava algumas estratégias, por exemplo, se você deu a medicação e molhar a sua boquinha antes de dar o prazo de você dar outra medicação, a criança já estava referindo dor outra vez, a gente tentava trabalhar, assim, distrair"

A enfermeira acredita estar confortando a criança oferecendo um tempo maior quando tem que realizar o procedimento novamente, tentando acalmá-la.

"se é um bebezinho, confortar, deixá-lo calmo, porque, geralmente, quando você vai puncionaré porque já perdeu, então ele está fazendo soroma, tem esse detalhe importante. Então, assim, acalmar, confortar, dar um tempinho para depois puncionar"

A tentativa da enfermeira em aliviar a dor da criança se dá também consolando a criança, quando a enfermeira demonstra sua afeição à criança. A enfermeira sabe que sua atitude concentra-se apenas em amenizar o sofrimento da criança, mas é o que pode fazer no momento.

"demonstrar que você gosta dela, acho que assim ela se sente um pouco mais confortada, você não vai tirar a dor"

\section{B- Tentar ajudar a família}

A tentativa da enfermeira em ajudar a família da criança com dor aparece ao acreditar que suas ações permitirão maior bem estar à família.

Conversar com a família faz parte da estratégia da enfermeira que vê nessa iniciativa sucesso no sentido de ir acalmando os pais quando percebem a criança com dor. A enfermeira passa grande parte do seu tempo junto com a família tentando conversar e acompanhando os pais até o leito da criança.

"então, primeiro acalmar os ânimos dos pais e tentar passar de forma mais verdadeira possível o que é que está acontecendo e depois ir junto com eles até o leito e tentar mostrar cada coisa do que está acontecendo"

Assim como conversar com a família é uma estratégia da enfermeira para acalmar os pais, ir explicando as coisas que acontecem com a criança também é outra estratégia utilizada pela enfermeira para tentar ajudar a família a compreender o que acontece com a criança.

"eu consegui sempre passar para família o que essa criança está tendo"

A enfermeira vai confiando na família ao reconhecer como verdadeiro seu relato sobre a evolução da dor da criança, tornando seu relacionamento com a família mais próximo, principalmente, por partir da perspectiva da família para agir no alívio da dor da criança.

"então vamos partir do que essa mãe relata que ela faz para criança em casa, ela pega no colo, ela acaricia, o que que ela faz"

Outro recurso utilizado pela enfermeira é estar orientando a família a respeito do cuidado da criança com dor, fortalecendo os pais a enfrentar esta situação de grande sofrimento.

"o senhor (pai) pode ficar, o senhor pode fazer isso, o senhor pode fazer aquilo, é orientar porque ele não sabe, ele não tem obrigação de saber"

\section{C- Articular a equipe}

O empenho da enfermeira em buscar soluções para a dor da criança é revelado quando procura formar um elo de ligação entre a família e a equipe objetivando maior comunicação entre as pessoas a respeito de como aliviar a dor da criança. A enfermeira acredita que seu papel é articular as pessoas visando melhorar o cuidado à criança com dor e sua família.

"o que eu fiz, convoquei os anestesistas, então eu fui, assim, formando um elo de ligação. Então eu peguei 0 anestesista e coloquei junto com a mãe" 


\section{DISCUSSÃO}

Ter realizado este estudo desencadeou muitas reflexões, levando-nos a compreender o quanto a enfermeira está presente no cuidado da criança que sente dor e de sua família, possibilitando-nos constatar o compromisso interno e a preocupação da enfermeira em aliviar a dor da criança e o sofrimento da família.

Consideramos que este compromisso interno da enfermeira é algo construído no cuidado cotidiano da criança e só se realiza face à presença da enfermeira durante a experiência de dor da criança. Na realidade, percebemos a enfermeira desejando eliminar a dor da criança e observamos este sentimento convergindo com o sentimento familiar, deixando claro a frustração sentida por ambos quando deparam-se apenas com o alívio da dor da criança.

De fato, os resultados deste estudo convergem com os de FERREIRA (1997), ao comentar que nem sempre as experiências em torno da pessoa sentindo dor são tranqüilas para enfermeira, ao contrário, os sentimentos de medo, impotência e insegurança expressados por ela só fazem revelar os próprios conteúdos humanos que estão presentes no processo de cuidar da pessoa que sente dor.

Desta forma, observando os resultados encontrados nesta investigação é possível reconhecer a congruência nos relatos das enfermeiras acerca de suas crenças ao cuidar da criança sentindo dor e sua família com o conteúdo exposto por Wright et al (1996) em seu trabalho quando definem crença como sendo a "verdade" de uma realidade subjetiva que influencia a estrutura e o funcionamento biopsicossocial e espiritual.

Ao entrarmos em contato com o trabalho de Wright et al (1996), constatamos que as crenças podem ser boas ou más para a saúde de alguém, podem facilitar, aumentando a possibilidade de solução do problema ou desencorajar a atitude da pessoa, dificultando a solução do problema.

Percebemos, então, o quanto as crenças do profissional podem ajudar ou prejudicar o cuidado da criança com dor quando reconhecemos a nossa tendência em aceitar apenas informações que confirmem nosso ponto de vista existente e rejeitar idéias, opiniões que contradizem crenças estabelecidas.

Ao focalizarmos as crenças que a enfermeira possui, podemos notar suas ações frente ao cuidado da criança com dor e sua família e perceber seu sofrimento ao tentar ajudá-los a conseguir o alívio da dor desta criança.

Observamos, também, através dos resultados deste estudo, que a enfermeira desenvolve uma relação com a criança que sente dor e sua família, uma relação que permite-lhe conhecer, acreditar e entender a história de vida desta criança e desta família tornando o envolvimento essencial para o cuidado.

Esta relação desenvolvida com a criança e com a família possibilita o surgimento de uma ação da enfermeira que revela sua disponibilidade para cuidar e aliviar a dor da criança. Deste modo, o respeito pela queixa da criança e a consideração pela família que sofre ao ver seu filho sentindo dor também parece ter significado expressivo no empenho da enfermeira em aliviar a dor da criança.

Nesse caminhar todos sofrem, a criança porque sente dor, a família por ver seu filho sofrer e sentir-se de mãos atadas e a própria enfermeira ao perceber a criança e a família sofrendo. A enfermeira sente-se, muitas vezes, insegura e perdida por desconhecer qual caminho seguir, mas acima de tudo, por sentir-se impotente com a situação de dor da criança, sentimentos esses, expressados pela enfermeira, significando sua presença na experiência da criança com dor.

Estar a todo momento tentando ajudar a criança e a família, tentando aliviar a dor da criança, superando, de certo modo, sua insegurança e impotência, leva-nos a identificar na atitude da enfermeira uma dimensão moral, que a faz acreditar no compromisso de ajudar a criança e a família, à semelhança nos achados no estudo de Ferreira (1997).

Penticuff (1990) nos mostra, em seu estudo, o papel da enfermeira como defensora do potencial da criança ao considerar importantes algumas intervenções de enfermagem que devem ser seguidas, como aliviar a dor e o desconforto da criança, preparar, não apenas a criança para os procedimentos mas também sua família. Comenta, também, que a família deve ser incluída no planejamento do cuidado da criança bem como ser respeitada em suas decisões em relação à criança.

Aos poucos a enfermeira, por estar envolvida e acima de tudo por conhecer, acreditar e entender a criança e sua dor, busca informações que a torne mais apta para desenvolver aquilo que é seu objetivo final dentro desse processo, o cuidado da criança. 0 julgamento da enfermeira frente às manifestações e reações 
da criança será decisivo para que ela alcance o seu objetivo. Nesse sentido, o trabalho de McG rath; McAlpine (1993) vem corroborar nosso estudo ao revelar a enfermeira também considerando a influência dos aspectos psicológicos na experiência da dor da criança.

O compromisso profissional não permite que a enfermeira cruze os braços diante da dor da criança. Porém, este compromisso é insuficiente para explicar as atitudes por ela tomadas. Podemos recorrer à explicação de Ferreira (1997) que, na verdade, a enfermeira é imbuída por uma ética humana, e que esta vai às últimas conseqüências para tornar o seu cuidado, cuidado pleno.

Ao pensar em cuidado pleno remetemo-nos ao cuidado da família da criança com dor. É interessante notar, neste estudo, que a enfermeira não exclui a família da criança da experiência de dor. Ela considera, como refere Angelo (1999), a dor da criança vista como um evento familiar.

Assim, estar presente na experiência de dor da criança, leva a enfermeira a estar sensível às experiências da família, o que, segundo Angelo (1997), é peça fundamental para ser capaz de reconhecer a família como um fenômeno complexo de demanda e apoio em tempos difíceis, sobretudo na situação de doença.

Este estudo possibilitou-nos encontrar ressonância no trabalho de Thyer (1992), que constata a importância do reconhecimento da dor da criança para a enfermeira como uma entidade, mas só podendo obter este entendimento estando presente na experiência de dor da criança e de sua família, que ainda permanecem sem poder de comunicação da sua dor.

Neste sentido, acredito que a enfermeira deva valorizar a presença da família durante o tratamento da criança, como mostram Ferrell et al (1994), R hiner et al (1994) em seu estudo, onde enfatizam a oportunidade de convivência que a enfermeira tem, não apenas com a criança, mas também com sua família.

Ser capaz de reconhecer a família como um fenômeno complexo já é uma tarefa difícil, mas reconhecer os fatores culturais da dor parece estar aquém de ser completamente entendido. Leininger (1997) acredita que os fatores culturais podem ser a maior e significativa dimensão para entender a variabilidade das respostas à dor das pessoas, recuperação da doença, manutenção da saúde, bem como a prevenção da doença.

Existe muito ainda a ser pensado e realizado sobre o cuidado da criança com dor e sua família. Ao longo desses anos, percebemos inúmeras dificuldades na atuação da enfermeira para aliviar a dor da criança, no entanto, encerramos este estudo testemunhando a enfermeira atravessando barreiras visando 0 alívio da dor da criança e do sofrimento da sua família.

ABSTRACT: This study searched to identify the nurse's beliefs about caring for the child in pain and his family and her strategies caring for the child in pain and his family. The study used like methodological framework the Grounded Theory Methodology and like theoretical framework Symbolic Interactionism. The findings allowed according to identify three themes in the study, focusing on nurse's beliefs about pain with child: Believing that the child has different natures of pain, Believing that the people involved with the child's pain is suffering and Believing that the nurse's role in the child's pain is to help.

KEY WORDS: Family health; Nursing care; Pain; Child.

RESUMEN: Este estudio buscó compreender las creencias de la enfermera en relación al dolor del niño y su familia y las estrategias utilizadas por la enfermera para lidiar com este dolor. Fueron utilizados como referencial metodológico la Teoría Fundamentada en los Dados y como referencial teórico el Interaccionismo Simbólico. Los resultados permitieron identificar tres Temas que revelan las creencias de la enfermera como determinantes del cuidado de un niño com dolor: Acreditando que el niño tiene dolor de diferentes naturalezas, Acreditando que las personas involucradas com el dolor del niño sufren y Acreditando que el papel de la enfermera en el dolor del niño es ayudar.

PALABRAS CLAVES: Salud de la familia; Atencion de enfermeria; Dolor; Niño. 


\section{REFERÊNCIAS BIBLIOGRÁFICAS}

1. ANGELO, M. Coma família em tempos difíceis: uma perspectiva de enfermagem. São Paulo, 1997. 117p. Tese (LivreDocente) - Escola de Enfermagem, Universidade de São Paulo.

2. ANGELO, M. A família da criança com dor. São Paulo, 1999. mimeografado.

3. CHARON, J .M. Symbolic interactionism: an introduction, an interpretation, an integration. 3rd, Englewood Cliffs : Prentice Hall, 1989.

4. CHENITZ, W,C.; SWANSON, J.M. From practice to grounded theory: qualitative research in nursing. San Francisco : Addison-Wesley, 1987.

5. DE NZIN, N.K. Interpretative interactionism. Newbury Park : Sage Publications, 1989.

6. FERREIRA, P. J . O. O cuidar humano/profissional da pessoa que sente dor: virtudes de uma prática que visa o bem. São Paulo,1997. 156 p. Dissertação (Mestrado) - Escola de Enfermagem, Universidade de São Paulo.

7. FERRELL, B.R. et al. The experience of pediatric cancer pain, Part I: impact of pain on the family. J. Pediatr. Nurs. Philadelphia, v.9, n.6, p.368-379, 1994.

8. FIELD, P.A.; MORSE,L.M. Nursing research: the application of qualitative approaches. Baltimore : Aspen, 1985.

9. LEININGER, M. Understanding cultural pain for improved health care. J . Transcult. Nurs., v.9, n.1, p.32-35, 1997.

10. McGRATH, P. J .; McALPINE, L. Psychologic perspectives on pediatric pain. J . Pediatr., St. Louis, v.122, n.5, Pt 2 S2-8, 1993.

11. PENTICUFF, J . H. E thics in pediatric nursing: advocacy and child's "determining self". Issues compr. Pediatr. Nurs., v.13, n.3, p.221-229, 1990.

12. RHINER, M. et al. The experience of pediatric cancer pain, Part II: Management of pain. J . Pediatr. Nurs., Philadelphia, v.9, n.6, p.380-387, 1994.

13. STRAUSS, A. L.; CORBIN, J. Basics of qualitative research: grounded theory procedures and techniques. New Bury Park : Sage Publications, 1990.

14. THYER, S. Pediatric pain- concepts for caring.. Contemp. Nurse, v.1, n.1, p.27-32, 1992.

15. WRIGHT, L. M.; WATSON, W. L.; BELL, J . M. Beliefs - The heart of healing in families and illness. New York : Basic Books, 1996. 